\title{
Performance Analysis of Autonomous Microgrid Subsequent to Symmetrical and Unsymmetrical Fault Triggered Condition
}

\author{
Chitra Natesan, ${ }^{1}$ Senthil Kumar Ajithan, ${ }^{2}$ Shobana Mani, ${ }^{1}$ \\ Priyadharshini Palani, ${ }^{1}$ and Prabaakaran Kandhasamy ${ }^{3}$ \\ ${ }^{1}$ Department of Electrical \& Electronics Engineering, SKP Engineering College, Anna University \& Asso., \\ Tiruvannamalai 606611, India \\ ${ }^{2}$ Department of Electrical \& Electronics Engineering, Velammal Engineering College, Chennai 600066, India \\ ${ }^{3}$ Department of Electrical \& Electronics Engineering, Sri Rangapoopathi College of Engineering, Gingee 604151, India
}

Correspondence should be addressed to Chitra Natesan; psk_siva@hotmail.com

Received 6 May 2014; Revised 28 June 2014; Accepted 28 June 2014; Published 4 August 2014

Academic Editor: Guanghui Wen

Copyright (c) 2014 Chitra Natesan et al. This is an open access article distributed under the Creative Commons Attribution License, which permits unrestricted use, distribution, and reproduction in any medium, provided the original work is properly cited.

\begin{abstract}
Hi-tech scenario and the ecological compression are the key point to drive the intervention of the renewable in the distribution system. In the perspective of complex power system planners, the transient performance of the microgrid is the main concern. For that purpose, various fault cases are explored in order to examine the microgrid transient performance when subjected to accidental events. In this work, the microgrid is modelled with two distributed generations (DGs) tied with a converter separately. With this intention, droop control strategy is adopted for the microsources to examine the microgrid performance during the symmetrical and unsymmetrical fault events. The ability of the control strategy adopted in this work and its effectiveness are evaluated through Matlab/Simulink platform.
\end{abstract}

\section{Introduction}

A new concept of microgrid (MG) was introduced with the help of power electronic devices and renewable energy sources. DG is considered to be a supplementary source of power in addition to the centralized power generation. Microsources and distributed generation combined with controllers, loads, and storage devices in order to compose a microgrid structure. Usually the microgrid sources are diesel generators, fuel cells, solar cells, and wind turbine. Distributed generations are usually combined with power electronic devices to get contact with the microgrid. DG interfaced with inverter can reduce oscillation throughout its fast control action [1].

Grid-tied mode and autonomous mode are the functions of microgrid system on the basis of static transfer switch position [2]. In case of any interruption, the microgrid should work on island mode to meet the demand in load. Also it should maintain power quality accordingly [3].
In case of real time, DG will breakdown accidentally or sometimes intentionally. So it has to provide uninterrupted supply; the microgrid has to sense mode of operation and switch to island mode in order to meet voltage supply for sensitive devices. This scenario is tough in real time for the power companies to provide reliable power supply [4]. But, in current industrial plot, it must detach DGs for the safety purpose. It also retards from switching to island mode to maintain protection constraints in distribution system.

Various research papers are discussed under the concept of transient stability subsequent to fault condition [5-11].

The author in [5] explores a new perspective by introducing different control strategies such as master slave approach and droop control approach for the transient stability analysis in a microgrid subsequent to fault triggered incident. In this work, diesel based generators and inverter based DG are composed. For inverter based DG, two control schemes such as real and reactive power $(P$ and $Q)$ control and current 


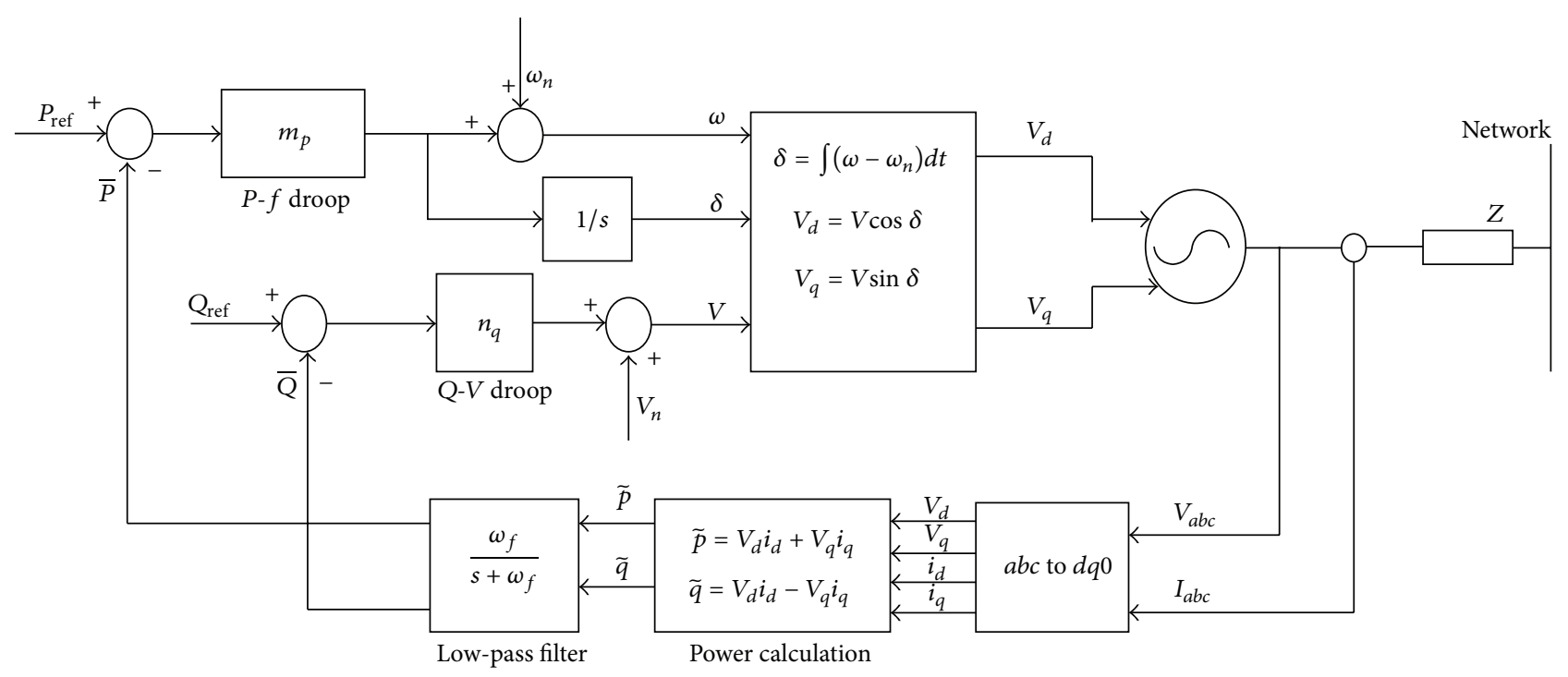

FIgURE 1: Droop control block diagram.

control scheme are introduced. Further, the author concluded that the droop control approach is best suited for subsequent transient incidents and $P$ and $Q$ control scheme holds good for inverter based DG.

Since the mechanism of microgrid operation differs from the traditional power grid, it is necessary to opt for the separate transient performance analysis [7]. So a dynamic model is projected for a microgrid to promote the difference among the microgrid and traditional grid transient analysis. In this work, differential algebraic equation is composed in order to model the dynamic system.

A new dimension of approach was conferred [8] about the transient stability in the course of network disruption in a wind farm when it is connected to a complex power system. To enhance the transient stability performance, superconducting magnetic energy storage (SMES) based controlled adaptive artificial neural network (ANN) was adopted. The SMES function on the basis of three criterions such as (i) voltage source converter (VSC), (ii) sinusoidal pulse width modulation (PWM), and (iii) an ANN controlled DC-DC converter using insulated gate bipolar transistors (IGBTs). Further, the ANN is compared with proportional integral (PI) on the basis of SMES control which is optimized by response surface methodology and genetic algorithm (RSMGA) in view of both symmetrical and asymmetrical faults. Hence, in conclusion, the transient performance is better while adapting ANN controller than PI controller.

Another interesting technique was categorized in [9]; the effectiveness of two different models of doubly fed induction generator (DFIG) wind turbine is compared, that is, DFIG with dynamic voltage restorer (DVR) and DFIG with crowbar protection under different fault conditions. In the model of DFIG with crowbar protection, the reactive power production was found to be more complicated, whereas the model of DFIG with DVR helps to compensate the fault voltage so that the DFIG wind turbine provides an uninterruptable power supply as per the load demand without the need of any additional protection.

Another novel approach attempted in [10] is the enhancement of microgrid performance during fault conditions with the battery energy storage system controller (BESS). But it has the restrictions for the sustainable operation; that is, the remnant energy of BESS must be zero.

The author in [11] introduced a dynamic model for the general microgrid under different conditions such as island operation, emergency control function, and service restoration in case of block-out. Therefore, the author defined a new control procedure for microgrid operation and management in LV distribution networks. In addition, controllable loads are also modelled, which are in desperate need of load shedding.

When $n$ number of inverter based DGs are connected in parallel to a microgrid system, there may raise problem in standalone operation, that is, less inertia which leads to either supply or consumption of energy during transient period. To resolve this problem, the author in [6] theoretically studied the small signal stability through Eigen value analysis.

It is compulsory to evaluate transient instability in order to prevent transient overloads. Highly dangerous transient overloads take part even though microsources are interconnected with power electronic devices [12]. Microgrid works parallel to main grid unless there is a fault in the system. It is hard to protect system from fault condition in case of grid connected mode. So the microgrid will operate separately after the fault event [13].

Concerning these common transient issues, a control strategy is developed to examine the performance of the microgrid. $P-F$ and $Q-V$ droop control are adopted to examine its impact during the transient stability period (Figure 1). Generally, the main use of the above method is to share appropriate power to DGs with the help of maintaining frequency and voltage $[14,15]$. 


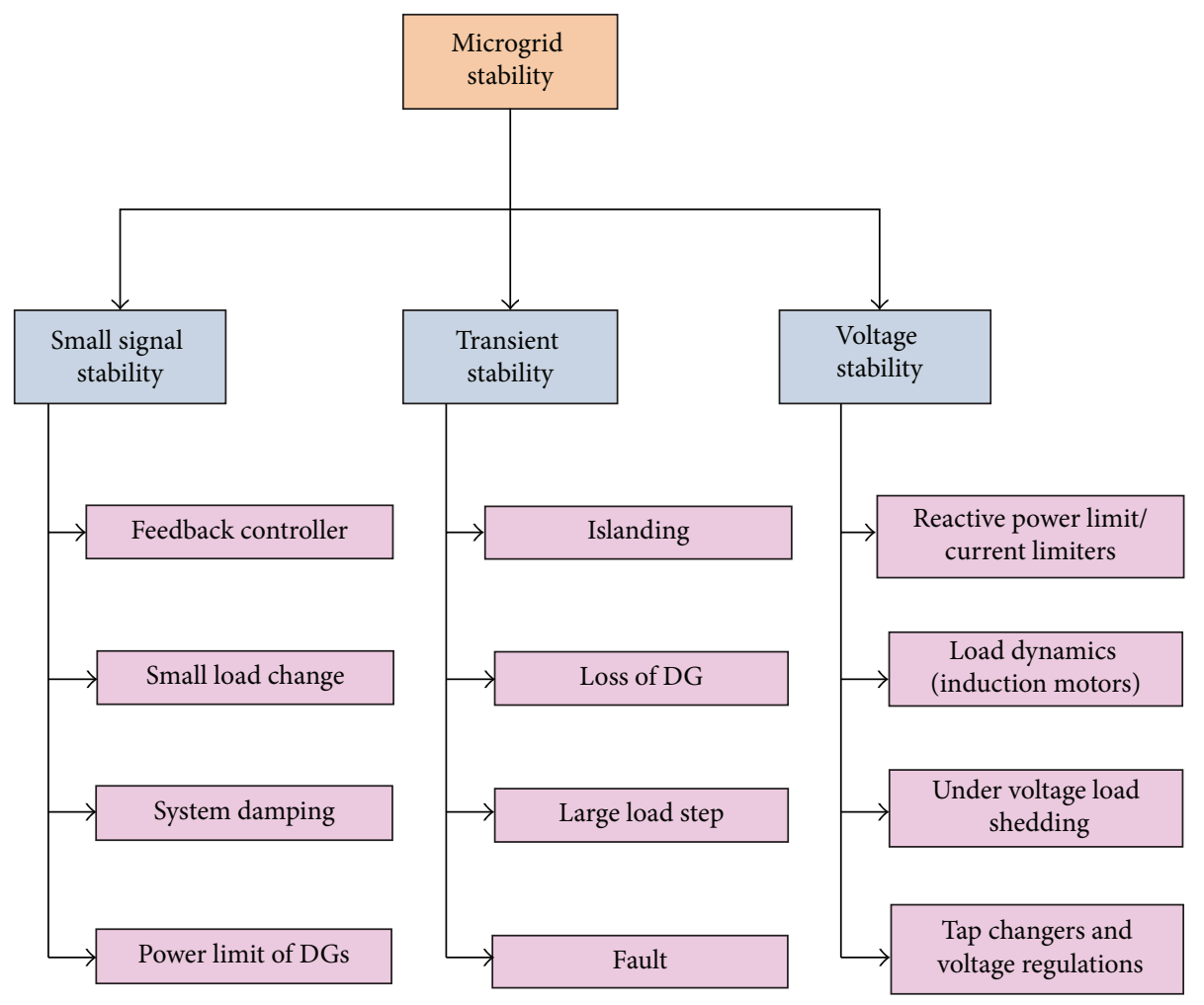

FIGURE 2: Different stability issues in microgrid.

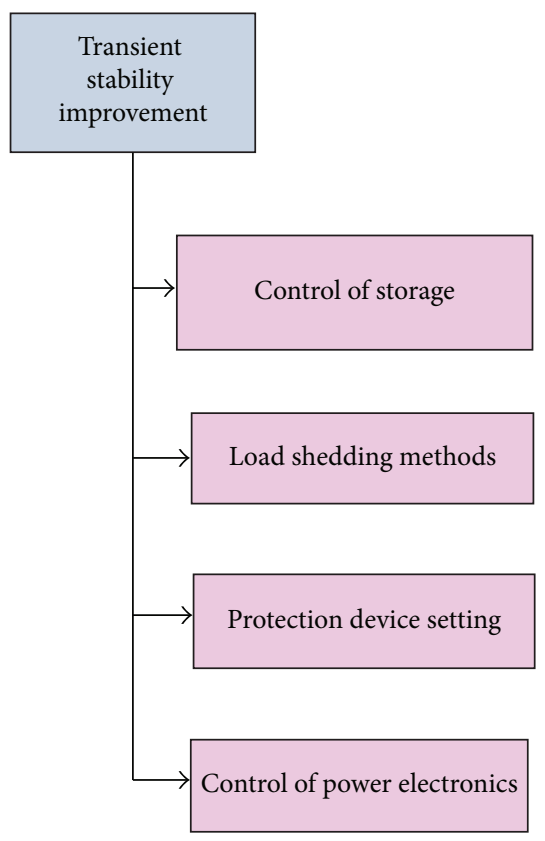

FIgURE 3: Different transient stability improvement methods.

The impact of droop control technique and the stability of the DG based on inverter arrangement of microgrid consequent to fault-forced autonomous circumstances are examined in this work. Further, the microgrid stability performance is scrutinised with induction motor (IM) loads.
Fault point $\mathrm{F} 1$

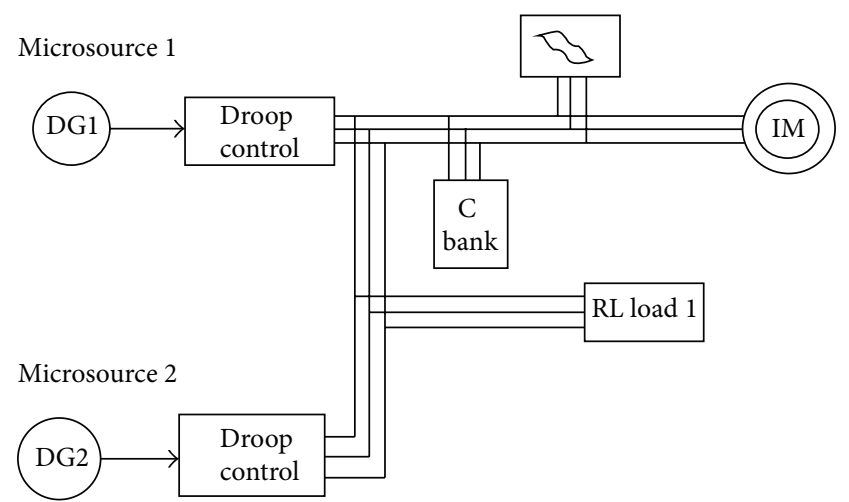

FIGURE 4: Single line layout of the utility and microgrid systems.

MatLab/Simulink and its libraries (mainly the sim power systems toolbox) were employed in order to develop a simulation platform suitable for identifying MG control requirements and evaluating MG dynamic behaviour under several operating conditions.

\section{Control Strategies}

In microgrid, the system reliability and stability are achieved only by the voltage regulation when more microsources are interconnected. This voltage regulation damps the reactive power oscillations and voltage [16]. In a complex power 


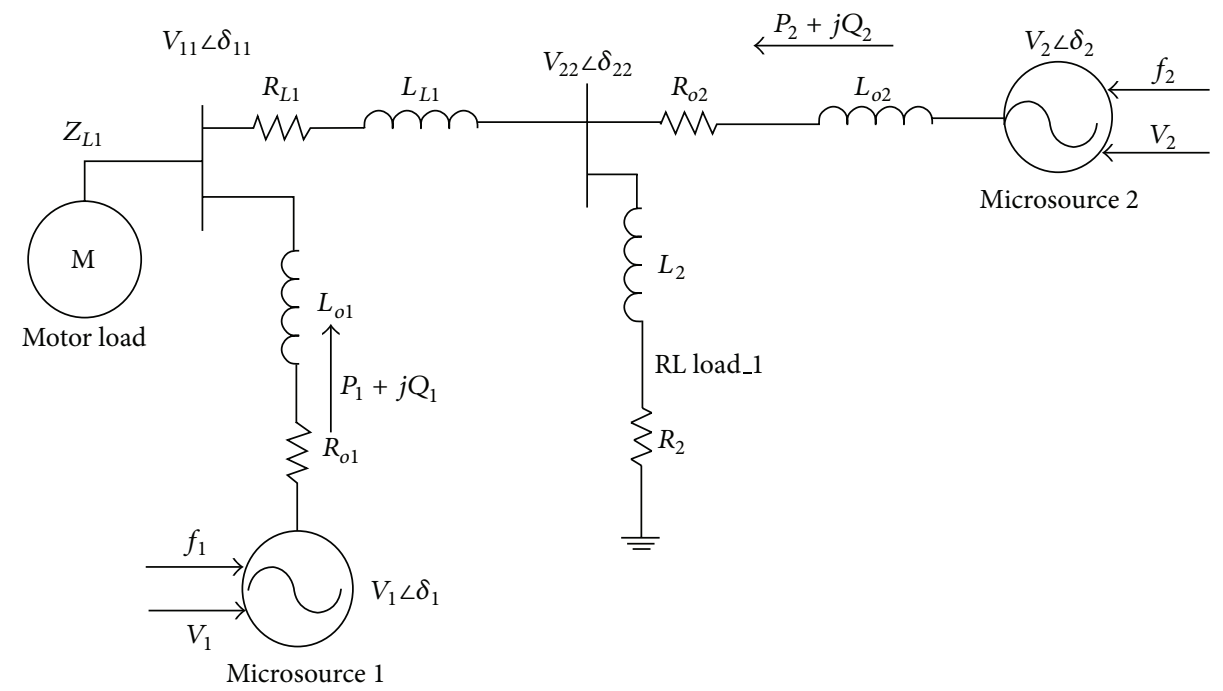

FIGURE 5: Equivalent model of the microgrid systems.

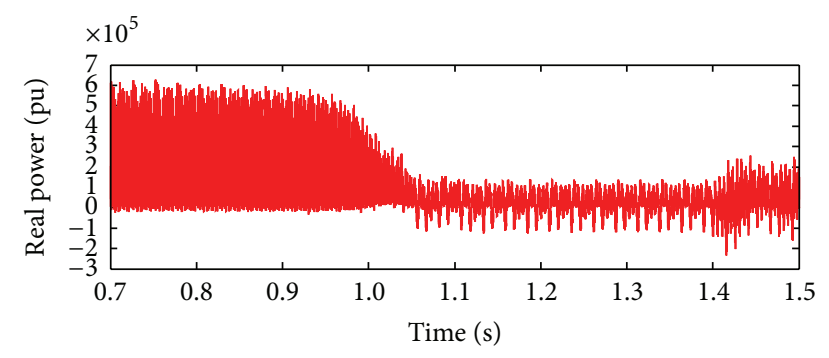

FIGURE 6: Real power during L-G fault.

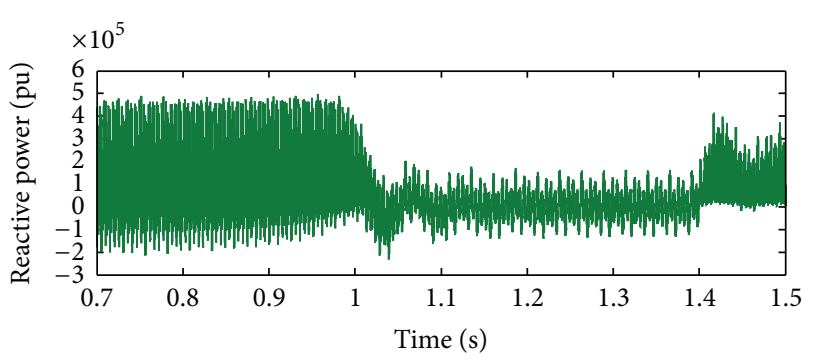

FIGURE 7: Reactive power during L-G fault.

system, when multiple DGs are attached to the microgrid, the power sharing among them is made properly with the help of a control strategy called droop control. Droop control also enables the system to disconnect smoothly and reconnect routinely to the complex power system [17].

The role of droop control in this work is that it controls the real power on the basis of frequency droop control and it controls the reactive power on the basis of voltage control $[18,19]$. The voltage and frequency can be manipulated by regulating the real and reactive power of the system. This forms a droop control equation.

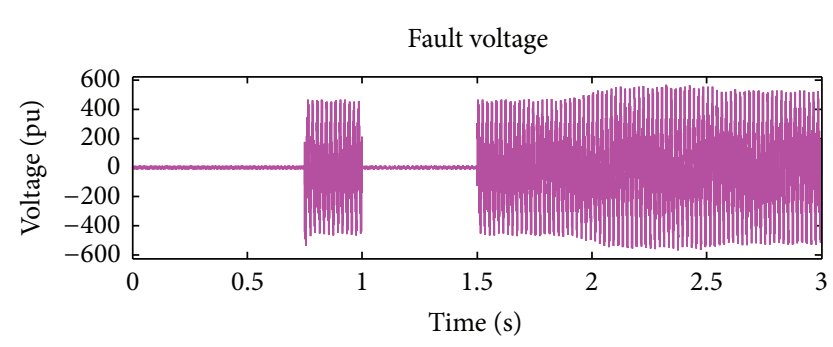

FIGURE 8: Load voltage during L-G fault.

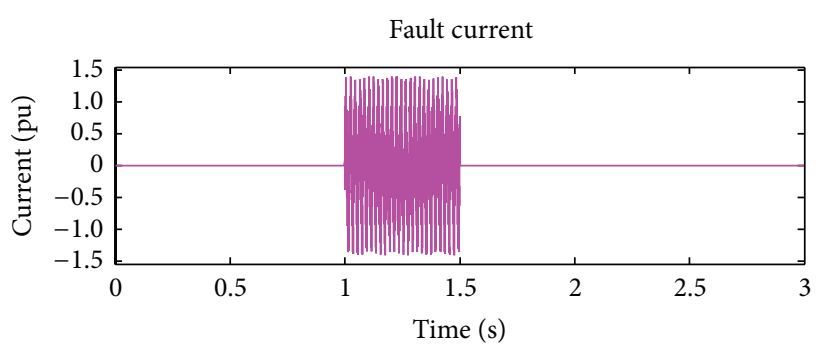

FIGURE 9: Load current during L-G fault.

In a transmission line, the real and reactive power are designed as

$$
\begin{gathered}
P=\frac{V 1 V 2}{X} \operatorname{Sin} \delta \\
Q=\frac{V 1^{2}}{X}-\frac{V 1 V 2}{X} \operatorname{Cos} \delta .
\end{gathered}
$$

In the abovementioned equation (1), resistance $(R)$ is neglected for overhead transmission lines as it is much 


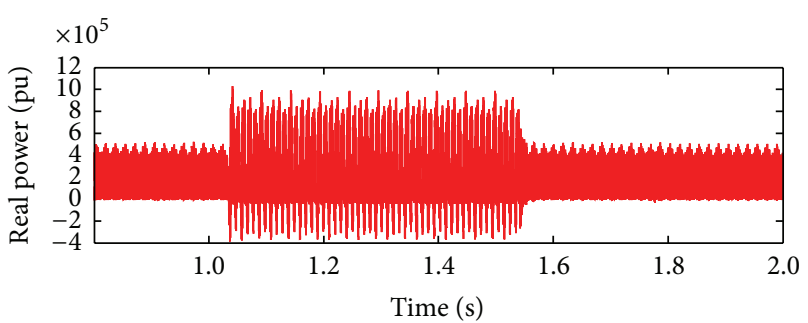

FIgURE 10: Real power during L-L fault.

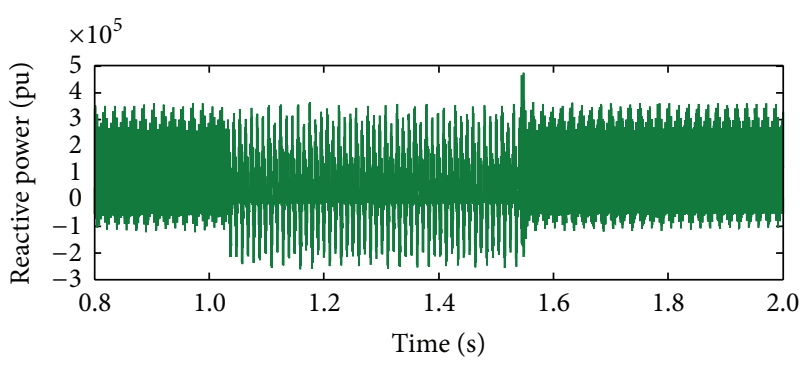

FIGURE 11: Reactive power during L-L fault.

lower than inductance $(L)$. Also the power angle $\delta$ is lesser. Therefore, $\sin \delta=\delta$ and $\cos \delta=1$.

$$
\begin{gathered}
\delta=\frac{X P}{V 1 V 2}, \\
V 1-V 2 \cong \frac{X Q}{V 1} .
\end{gathered}
$$

Hence, from the above equation (2), it is clear that the power angle $\delta$ can be controlled by regulating real power $P$. Also, the voltage $V 1$ can be controlled through reactive power Q. Dynamically, the frequency control leads to regulating the power angle and this in turn controls the real power flow [20]. Finally, the frequency and voltage amplitude of the microgrid are manipulated by adjusting the real and reactive power autonomously. As a result, the frequency and voltage droop regulation can be determined as

$$
\begin{gathered}
f-f_{0}=K_{p}\left(P-P_{0}\right), \\
V-V_{0}=K_{q}\left(Q-Q_{0}\right) .
\end{gathered}
$$

The relationship between real power, frequency, and reactive power, voltage, can be manipulated from (3):

$$
\begin{aligned}
& f=f_{0}+K_{p}\left(P-P_{0}\right), \\
& V=V_{0}+K_{q}\left(Q-Q_{0}\right),
\end{aligned}
$$

where $f, V=$ the frequency and voltage at a new operating point. $P, Q=$ active and reactive power at a new operating point. $f_{0}, V_{0}=$ base frequency and voltage. $P_{0}, Q_{0}=$ temporary set points for the real and reactive power. $K_{p}, K_{q}=$ droop constant.
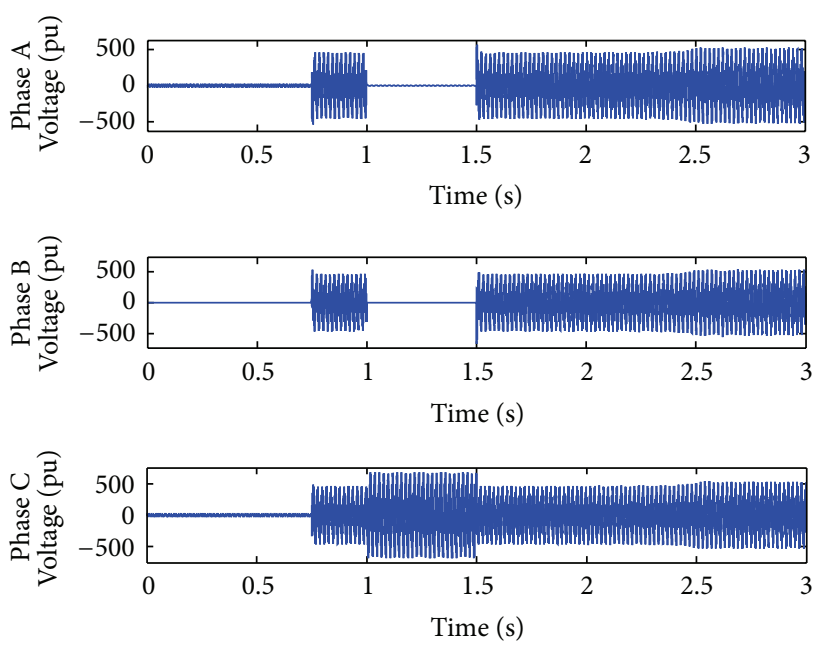

FIGURE 12: Load voltage during L-L fault.
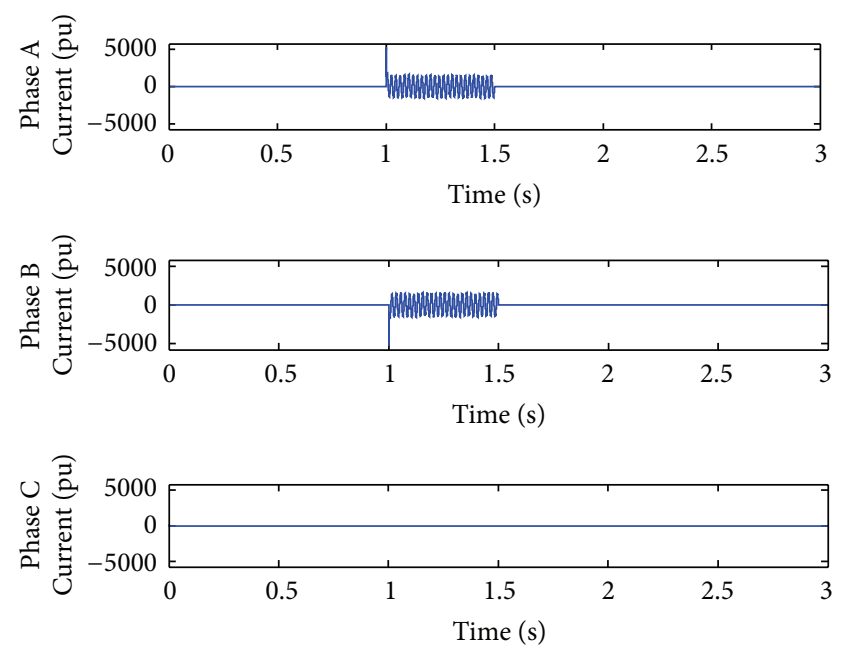

FIGURE 13: Load current during L-L fault.

\section{Stability Analysis}

In recent researches, the stability issue in the microgrid seems to be gaining its attention. The power system engineers chiefly focus the restructuring in the power system particularly when exposed to a severe disturbance. Typically, the system designers target the aspect of reliable and stable power supply as per their load demands [21, 22]. Among various stability issues of microgrid, transient stability alone is considered in this work. In course of islanding process, the transient effects depend on the criterions such as (i) working conditions before islanding and (ii) the events which cause islanding. Even though it may be planned or unplanned islanding, the microgrid is expected to stay in working condition. Therefore, it is necessary to enhance the dynamic response of the microgrid [23].

3.1. Transient Stability. Even at more disturbances, the microgrid can perform its action without any interventions. This 


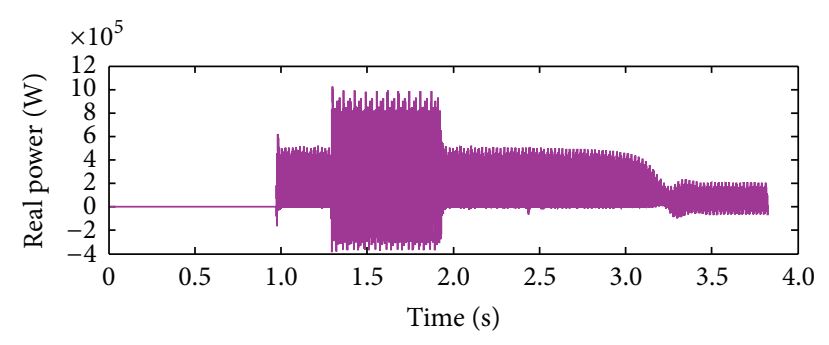

FIGURE 14: Real power during LLG fault.

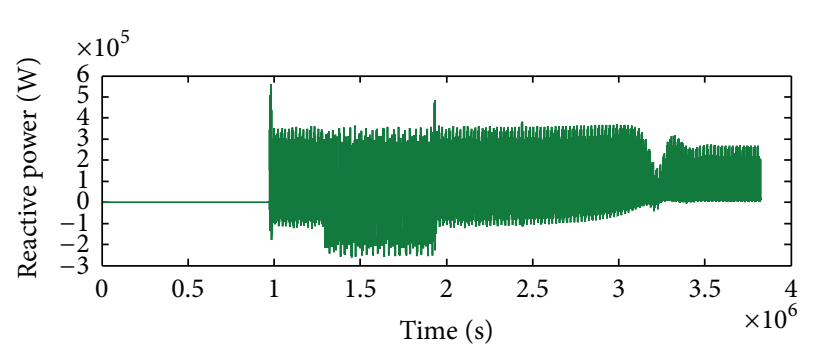

FIGURE 15: Reactive power during LLG fault.

function changes the microgrid mode from grid-tied mode to island mode. There is a possibility of occurrence of heavy disturbance in power system due to switching of heavy loads or transmission line fault. Hence, this disturbance will lead to synchronisation loss in the system. It is represented as transient stability [24]. In recent times, many system stability issues have been researched and some stability improvement methods have been developed which are shown in Figures 2 and 3. Control strategies, microsources, and type of microgrid are the main parameters of stability. All the microsources are connected to power electronic devices, that is, here voltage source inverter. So the control method of power electronic devices controls the stability $[25,26]$.

\section{Simulation Model}

The microgrid is modelled with two microsources which have a DC source as input and the $P-F$ and $Q-V$ droop control have been employed. At the time of starting, RL load is connected to the system as shown in Figure 4 and its equivalent model is shown in Figure 5. In order to highlight the performance difference of microgrid when connected with normal load and nonlinear load, induction motor is connected at $0.75 \mathrm{sec}$ and disconnected at $2.5 \mathrm{sec}$. As a next, study about the activity of microgrid with RLload during fault triggered incident is analyzed. To perform this activity, a LG fault was introduced for a period of 1 to 1.5 secs. This microgrid system has been simulated under the Matlab/Simulink software environs.

\section{Simulation Result}

With the intention of authenticating the aforesaid control strategies, AC system was programmed to evaluate its performance when subjected to various faults. The symmetrical and unsymmetrical fault analysis was implemented in
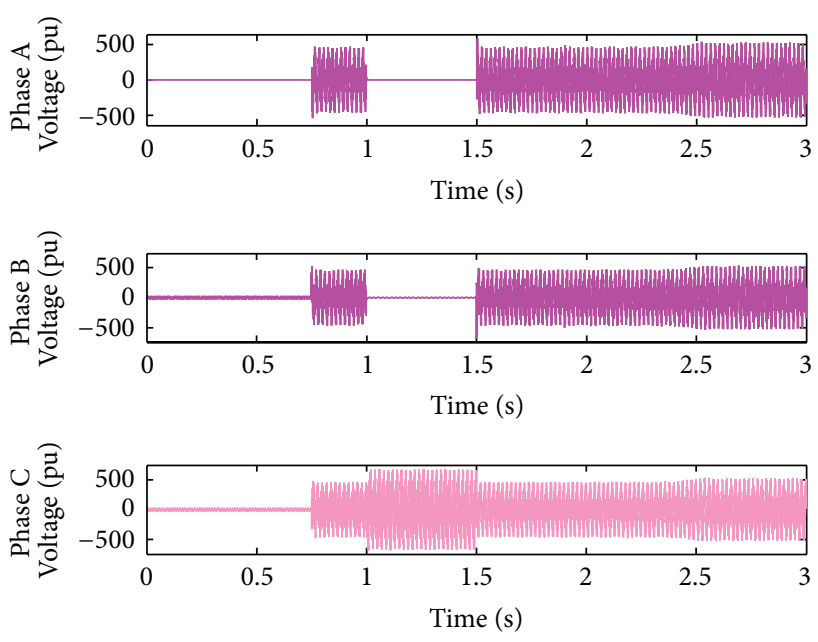

FIGURE 16: Fault voltage during LLG fault.
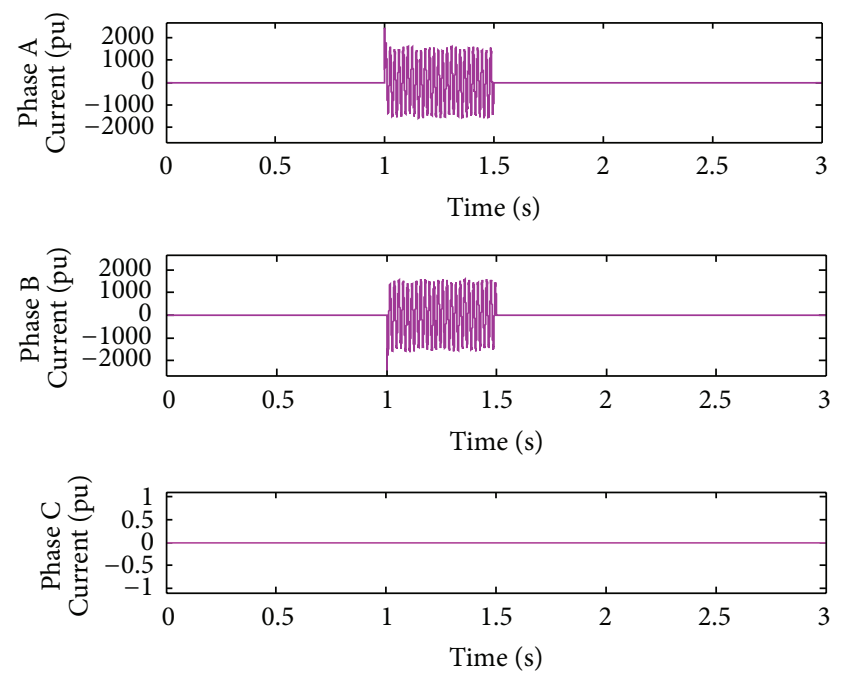

FIGURE 17: Fault current during LLG fault.

a Matlab/Simulink platform. The parameters such as real and reactive power, fault voltage, fault current, and the rotor speed waveforms are presented for all the faults in Figures 4 and 5.

Case 1. LG fault occurs on phase A. The single line to ground fault occurs on phase A. The duration of the fault period is from $1 \mathrm{sec}$ to $1.5 \mathrm{sec}$. After $1.5 \mathrm{sec}$, induction motor load will act, and this results in a gradual increase for a short duration and then it attains constant. The real and reactive power behaviour during faulty period is exposed in Figures 6 and 7. Initially, the voltage on the IM load side is zero as the IM load is included only at $0.75 \mathrm{sec}$. The IM load voltage is at $440 \mathrm{~V}$ as soon as the motor starts but it instantly drops to zero when the L-G fault occurs, that is, at $1 \mathrm{sec}$. So the load voltage remains at zero until the L-G fault is recovered, that is, till $1.5 \mathrm{sec}$. After $1.5 \mathrm{sec}$, the load voltage increases to $440 \mathrm{~V}$. Similarly, during fault event, the fault current will increase to its maximum value of $1.5 \mathrm{~mA}$ from $1 \mathrm{sec}$ to $1.5 \mathrm{sec}$. It will 


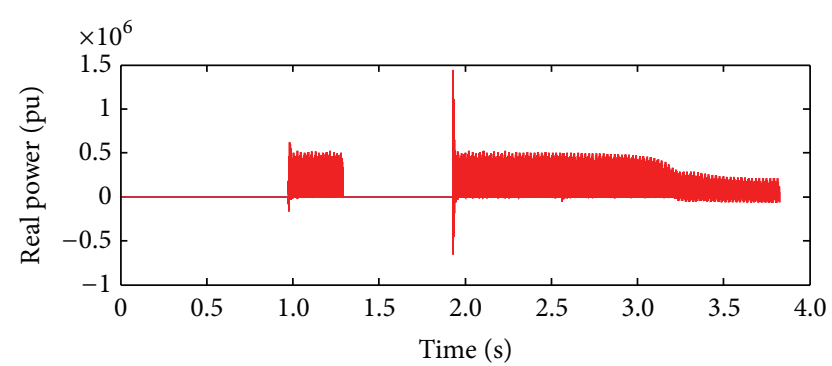

FIGURE 18: Real power during LLLG fault.

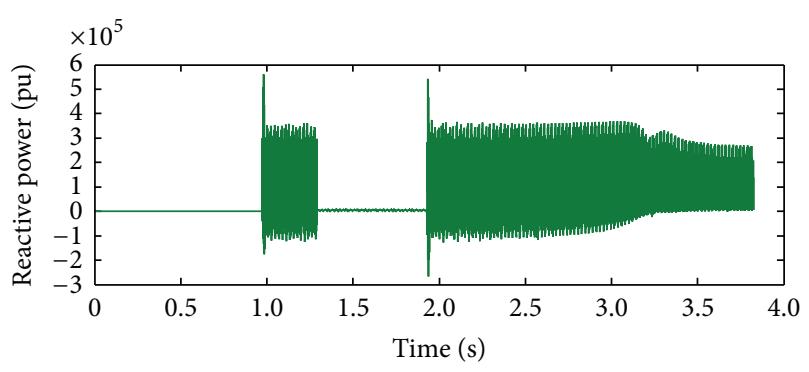

FIgURE 19: Reactive power during LLLG fault.

remain zero throughout the operating period as illustrated in Figures 8 and 9 .

Case 2. LL fault occurs on phase A and phase B. The line to line fault occurs on phase A and phase B. The duration of the fault period is from $1 \mathrm{sec}$ to $1.5 \mathrm{sec}$. As illustrated in Figures 10 and 11, initially the real power maintains a constant value till $1 \mathrm{sec}$. From 1 to $1.5 \mathrm{sec}$, the real power shoots up drastically about $10 \mathrm{pu}$. After the fault period, it regains its original value. Figure 12 illustrates the load voltage on the IM load side performance during fault on phase $\mathrm{A}$ and phase $\mathrm{B}$. Voltage of phase A and phase B falls to zero, while voltage swell which exists in phase $\mathrm{C}$ can be seen during the faulty condition. In the same way, the current of phase A and phase $B$ shoots up to its maximum value, while the current of phase C remains zero, Figure 13.

Case 3. LLG fault occurs on phase A and phase B to ground. From Figures 14 and 15, the behaviour of the real and reactive power on source side during faulty condition is clearly revealed. Since phase A and phase B were affected by the fault, phase $C$ still continues to supply a maximum permissible power. At $1.5 \mathrm{sec}$, the circuit breaker connects the system and the IM load is included. As per Figures 16 and 17, the fault voltage and fault current fluctuate accordingly.

Case 4. LLLG fault-symmetrical fault. For the stability analysis, 3LG fault is also considered along with the asymmetrical fault. The fault occurs at the fault position F1 on the load side as shown in Figure 4. The real and reactive power on the source side and the voltage and current at the time of fault are projected. The real power and reactive power are controlled to the sufficient level during the fault period by means of the proposed droop control strategy. Figures 18 and 19 show the response of real and reactive power. The voltage and current
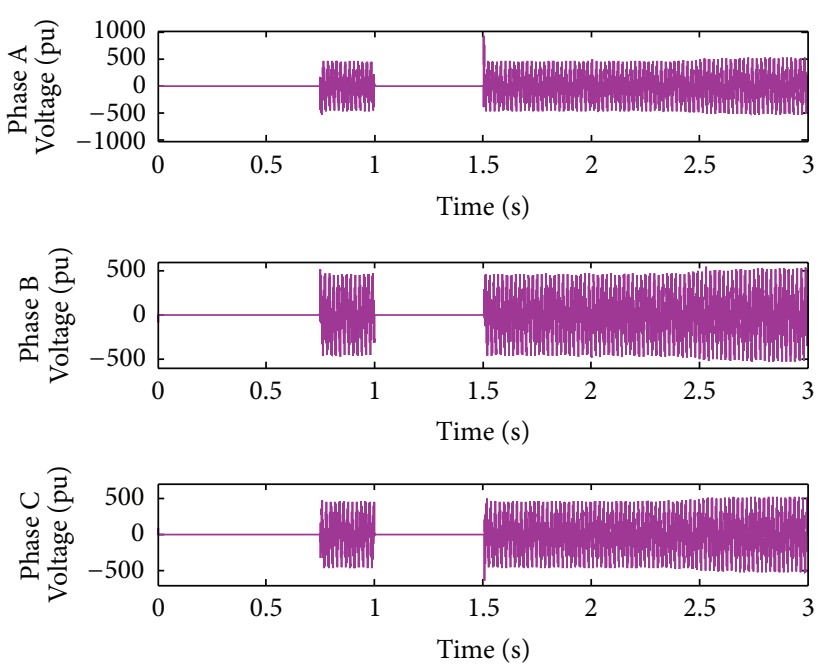

FIGURE 20: Fault voltage during LLLG fault.
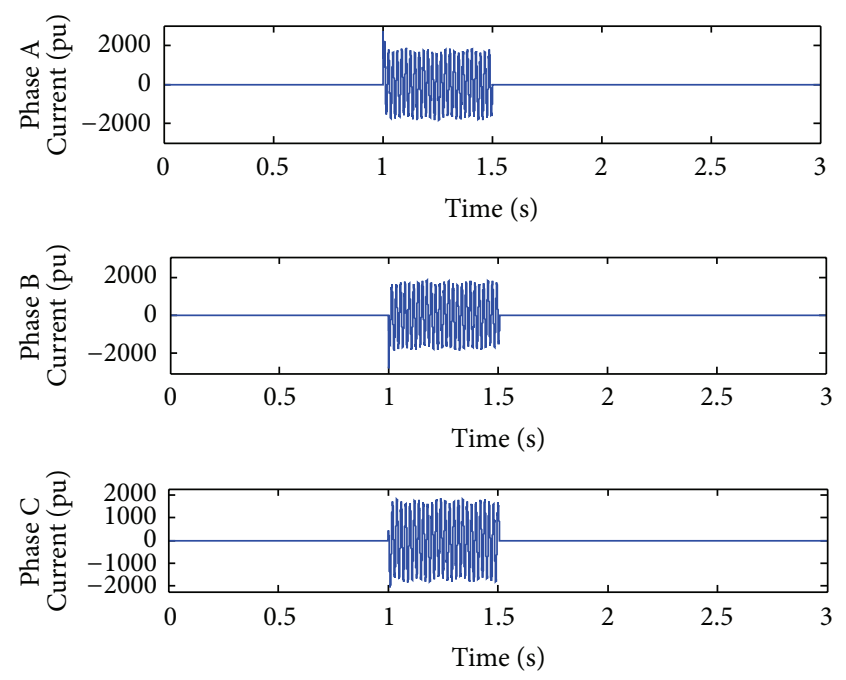

Figure 21: Fault current during LLLG fault.

behaviour on the faulty condition are presented in Figures 20 and 21 .

\section{Conclusion}

This paper explores the microgrid system behaviour when it is exposed to the consequent faults like symmetrical fault (LLLG) and asymmetrical fault (L-G, LL, and LLG). With this intention to enhance the system performance, droop control technique is adopted. Particularly P-F droop control technique is enabled for the inverter based DGs. For the simulation results, it is evidence that the droop control strategy enhances the performance of DGs during the various faults conditions and also when the DGs are connected to the IM load and RL load. The simulation results evidenced that the proposed power controller proffers an exceptional response in regulating the microgrid voltage and 
frequency with an allowable level of harmonic content during autonomous mode.

\section{Conflict of Interests}

The authors declare that there is no conflict of interests regarding the publication of this paper.

\section{References}

[1] Z.-x. Xiao and H.-w. Fang, "Impacts of P-f \& Q-V droop control on microgrids transient stability," Physics Procedia, vol. 24, pp. 276-282, 2012.

[2] S. M. Ashabani and Y. A. I. Mohamed, "A flexible control strategy for grid-connected and islanded microgrids with enhanced stability using nonlinear microgrid stabilizer," IEEE Transactions on Smart Grid, vol. 3, no. 3, pp. 1291-1301, 2012.

[3] C. X. Dou and B. Liu, "Transient control for micro-grid with multiple distributed generations based on hybrid system theory," International Journal of Electrical Power and Energy Systems, vol. 42, no. 1, pp. 408-417, 2012.

[4] I. J. Balaguer, Q. Lei, S. Yang, U. Supatti, and F. Z. Peng, "Control for grid-connected and intentional islanding operations of distributed power generation," IEEE Transactions on Industrial Electronics, vol. 58, no. 1, pp. 147-157, 2011.

[5] A. H. Kasem Alaboudy, H. H. Zeineldin, and J. Kirtley, "Microgrid stability characterization subsequent to fault-triggered islanding incidents," IEEE Transactions on Power Delivery, vol. 27, no. 2, pp. 658-669, 2012.

[6] M. Illindala and G. Venkataramanan, "Small signal stability of a microgrid with parallel connected distributed generation," Intelligent Automation and Soft Computing, vol. 16, no. 2, pp. 235-254, 2010.

[7] X. Xiong and J. Ouyang, "Modeling and transient behavior analysis of an inverter-based microgrid," Electric Power Components and Systems, vol. 40, no. 1, pp. 112-130, 2011.

[8] S. M. Muyeen, H. M. Hasanien, and A. Al-Durra, "Transient stability enhancement of wind farms connected to a multimachine power system by using an adaptive ANN-controlled SMES," Energy Conversion and Management, vol. 78, pp. 412420, 2014.

[9] C. Wessels, F. Gebhardt, and F. W. Fuchs, "Fault ride-through of a DFIG wind turbine using a dynamic voltage restorer during symmetrical and asymmetrical grid faults," IEEE Transactions on Power Electronics, vol. 26, no. 3, pp. 807-815, 2011.

[10] M. Jain, S. Gupta, D. Masand, and G. Agnihotri, "Analysis of a microgrid under transient conditions using voltage and frequency controller," Advances in Power Electronics, vol. 2012, Article ID 208231, 15 pages, 2012.

[11] C. L. Moreira and J. A. Peças Lopes, "Microgrids operation and control under emergency conditions," Intelligent Automation and Soft Computing, vol. 16, no. 2, pp. 255-272, 2010.

[12] R. M. Kamel, "Effect of wind generation system types on MicroGrid (MG) fault performance during both standalone and grid connected modes," Energy Conversion and Management, vol. 79, pp. 232-245, 2014.

[13] T.-C. Ou, "A novel unsymmetrical faults analysis for microgrid distribution systems," International Journal of Electrical Power \& Energy Systems, vol. 43, no. 1, pp. 1017-1024, 2012.
[14] H. Liang, B. J. Choi, W. Zhuang, and X. Shen, "Decentralized inverter control in microgrids based on power sharing information through wireless communications," in Proceedings of the IEEE Global Communications Conference (GLOBECOM '12), pp. 5148-5153, IEEE, December 2012.

[15] P. Rodriguez, A. V. Timbus, R. Teodorescu, M. Liserre, and F. Blaabjerg, "Flexible active power control of distributed power generation systems during grid faults," IEEE Transactions on Industrial Electronics, vol. 54, no. 5, pp. 2583-2592, 2007.

[16] J. A. P. Lopes, C. L. Moreira, and A. G. Madureira, "Defining control strategies for microgrids islanded operation," IEEE Transactions on Power Systems, vol. 21, no. 2, pp. 916-924, 2006.

[17] J. He and Y. W. Li, "An enhanced microgrid load demand sharing strategy," IEEE Transactions on Power Electronics, vol. 27, no. 9, pp. 3984-3995, 2012.

[18] R. Majumder, B. Chaudhuri, A. Ghosh, R. Majumder, G. Ledwich, and F. Zare, "Improvement of stability and load sharing in an autonomous microgrid using supplementary droop control loop," IEEE Transactions on Power Systems, vol. 25, no. 2, pp. 796-808, 2010.

[19] F. Razavi, R. Torani, I. Askarian, A. Asgharizadeh, and N. Masoomi, "Optimal design of islanded microgrid using genetic algorithm," in International Conference on Genetic and Evolutionary Methods (GEM '12), 2012.

[20] F. Shahnia, R. Majumder, A. Ghosh, G. Ledwich, and F. Zare, "Operation and control of a hybrid microgrid containing unbalanced and nonlinear loads," Electric Power Systems Research, vol. 80, no. 8, pp. 954-965, 2010.

[21] W. S. Lee and S. H. Kang, "Protection for distributed generations in the DC micro-grid," in Proceedings of the 2nd IEEE PES International Conference and Exhibition on Innovative Smart Grid Technologies (ISGT Europe '11), pp. 1-5, December 2011.

[22] R. Majumder, "Some aspects of stability in microgrids," IEEE Transactions on Power Systems, vol. 28, no. 3, pp. 3243-3252, 2013.

[23] S. Sanchez, M. Molinas, M. Degano, and P. Zanchetta, "Stability evaluation of a DC micro-grid and future interconnection to an AC system," Renewable Energy, vol. 62, pp. 649-656, 2014.

[24] M. B. Delghavi and A. Yazdani, "An adaptive feedforward compensation for stability enhancement in droop-controlled inverter-based microgrids," IEEE Transactions on Power Delivery, vol. 26, no. 3, pp. 1764-1773, 2011.

[25] X. Chen, W. Pei, and X. Tang, "Transient stability analyses of micro-grids with multiple distributed generations," in Proceeding of the International Conference on Power System Technology (POWERCON '10), pp. 1-8, Hangzhou, China, October 2010.

[26] J. V. Milanovic, M. T. Aung, and S. C. Vegunta, “The influence of induction motors on voltage sag propagation - Part I: Accounting for the change in sag characteristics," IEEE Transactions on Power Delivery, vol. 23, no. 2, pp. 1063-1071, 2008. 

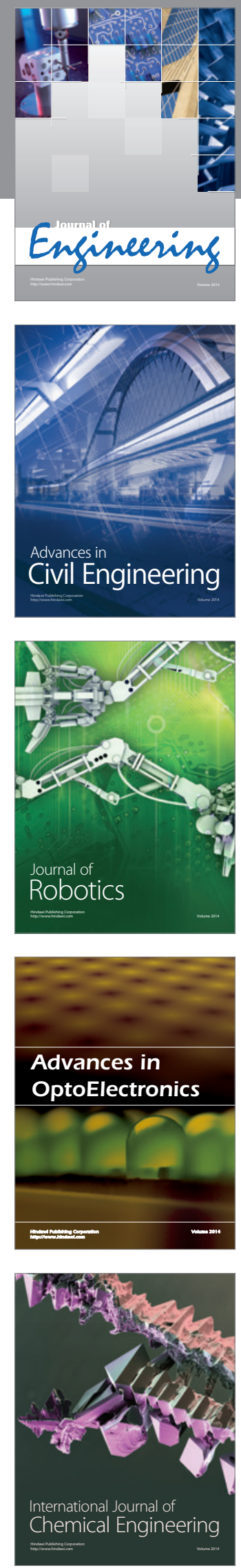

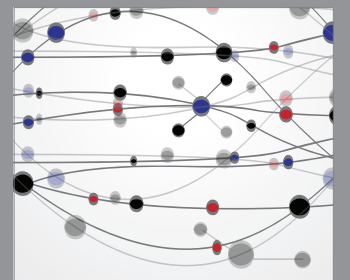

The Scientific World Journal
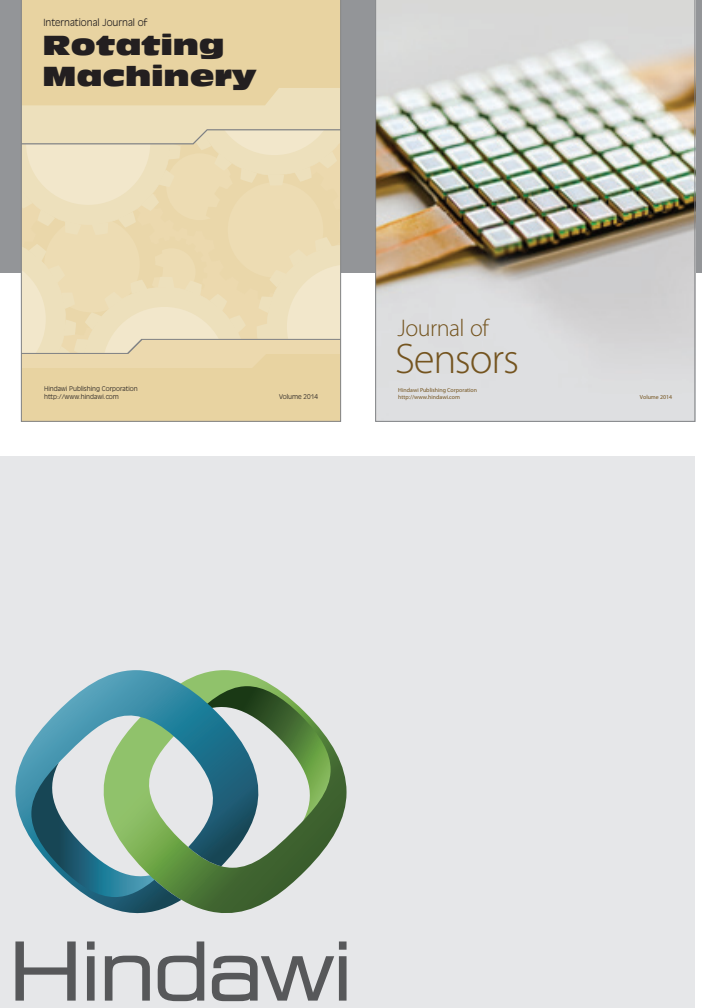

Submit your manuscripts at http://www.hindawi.com
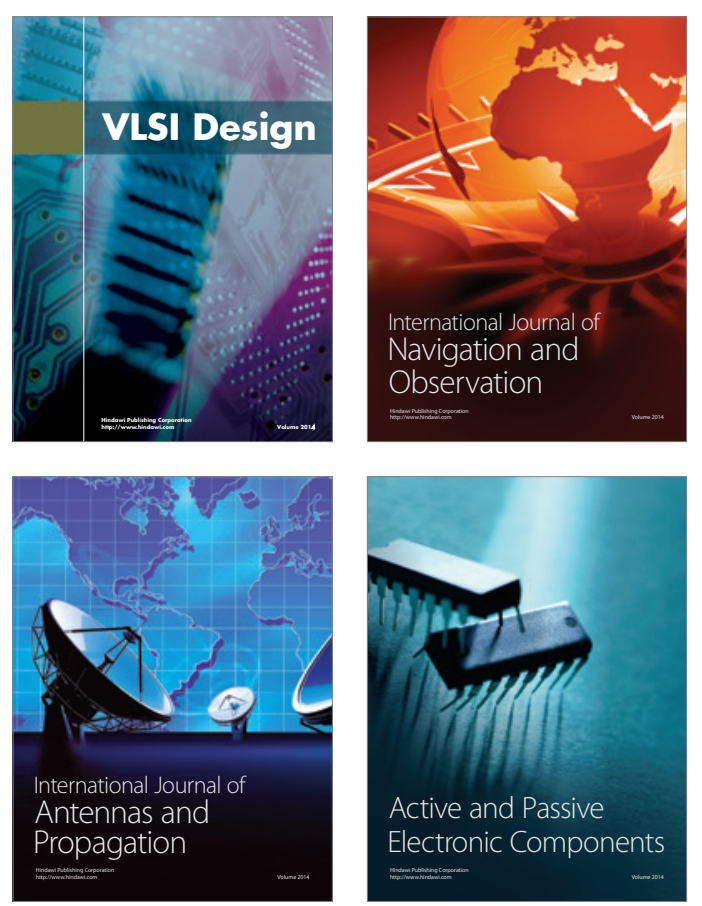
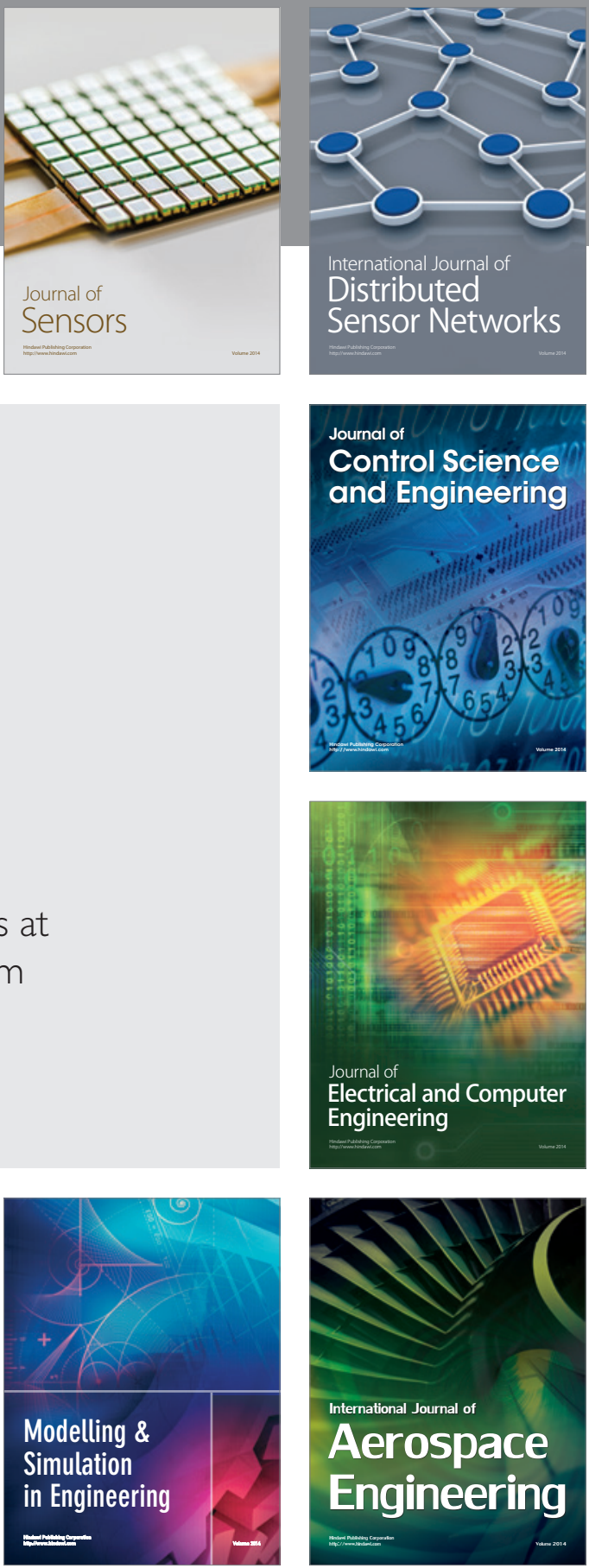

Journal of

Control Science

and Engineering
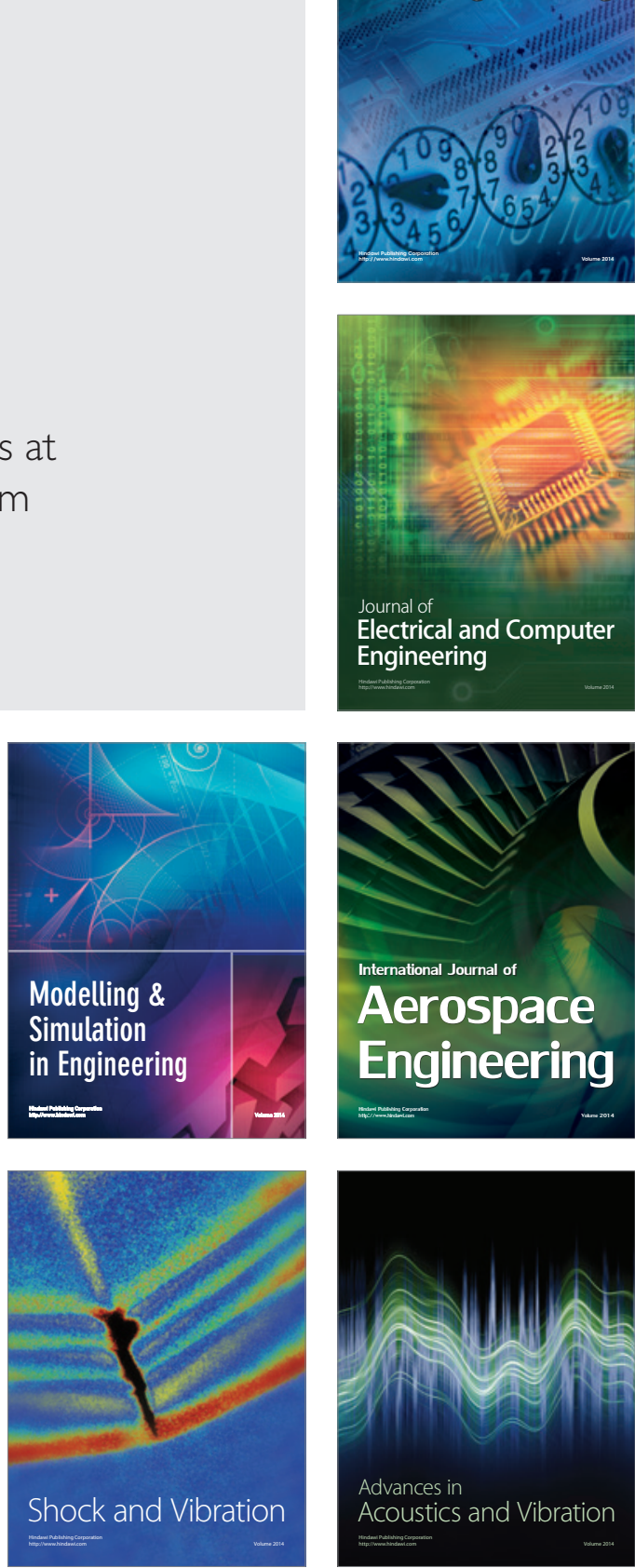